\title{
PRECEDING PHONOLOGICAL CONTEXT AND CLUSTER TYPE EFFECTS ON WORD- INITIAL /S/-CLUSTER PRONUNCIATION IN BRAZILIAN PORTUGUESE/ENGLISH INTERPHONOLOGY
}

Efeitos do contexto fonológico anterior e tipo de encontro consonantal na pronúncia de encontros

iniciados em $/ \mathrm{s} /$ no início de palavras na interfonologia do Português do Brasil/Inglês

\author{
Melissa Bettoni* \\ Fernando Rosseto Gallego Campos**
}

\begin{abstract}
RESUMO
Estudos mostram que brasileiros tendem a inserir uma vogal antes de palavras iniciadas por encontros consonantais do inglês iniciados por $/ \sigma /(/ \sigma \mathrm{C}(\mathrm{C}))$ e vozear o $/ \sigma /$ dependendo dos traços da consoante seguinte (e.g., CORNELIAN, 2003; RAUBER, 2006; REBELLO; BAPTISTA, 2006). A presente pesquisa investigou a percepção e a produção de $/ \sigma \mathrm{C}(\mathrm{C}) /$ no início de palavras na interfonologia do Português do Brasil/Inglês. Os dados da produção foram obtidos por três testes de leitura e

* Instituto Federal de Santa Catarina

** Instituto Federal de Santa Catarina
\end{abstract}


os dados da percepção foram obtidos através de um teste de identificação com duas alternativas com escolha forçada. 0 estímulo para o teste foi gravado por três americanos falantes nativos de inglês. $O$ objetivo principal do estudo foi verificar os efeitos do contexto fonológico e do tipo de encontro na quantidade de erros de produção e problemas na identificação, uma vez que estudos anteriores apontaram para tendências diversas em relação à produção, e a percepção ainda não havia sido investigada em relação a efeitos do contexto fonológico. Os resultados indicaram que o contexto fonológico não tem efeito significativo sobre a percepção e a produção de palavras iniciadas pelos encontros iniciados por $/ \sigma /$. Ainda, tanto a produção quanto a percepção de $/ \sigma /+$ sonora foram mais difíceis que de $/ \sigma /+$ plosiva para os informantes do estudo.

Palavras-chave: inglês como língua estrangeira; percepção $e$ produção; contexto fonológico.

\begin{abstract}
Research has shown that Brazilians tend to insert a vowel before word-initial $/ \sigma /$-clusters and to voice the $/ \sigma /$ depending on the following consonant features (e.g., CORNELIAN, 2003; RAUBER, 2006; REBELLO; BAPTISTA, 2006). The present study investigated the perception and production of $/ \sigma /$-clusters in the Brazilian Portuguese/English interphonology. Production was assessed by three reading tests and perception was assessed by a two-alternative-forced-choice identification test. The stimuli were recorded by three native speakers of American English. The main objective of the study was to verify whether phonological context and cluster type would affect amount of misproductions and misperceptions as previous studies have brought different conclusions regarding production, and perception had not been tested regarding preceding phonological context. The results showed that the preceding phonological context did not significantly affect perception and production even though a tendency was found and that $/ \sigma /+$ sonorant clusters were more difficult than $/ \sigma /+$ stop clusters in both perception and production.
\end{abstract}

Keywords: English as a Foreign Language; perception and production; phonological context.

\title{
1. INTRODUCTION
}

The perception and production of non-native contrasts is an important topic under investigation in the field of second language acquisition (SLA) (e.g., BAPTISTA, 2006; BEST, 1995; FLEGE, 1988, 1995; WATKINS, 
2000; KOERICH, 2002; SILVEIRA, 2004). The main reasons for carrying out studies in this area are to identify and to understand the difficulties foreign (FL) or second language (L2) learners have in pronouncing the target language; thus, providing support to further studies which can come up with ideas and pedagogical tools that can help learners overcome the difficulties pointed out.

The present study investigates the perception and production of a difficult non-native structure for Brazilians learners of English - word-initial $/ \sigma /$-clusters. Word-initial $/ \sigma /$-clusters were defined as the target structure in the study because the acquisition of $/ \sigma /$-clusters is difficult in both first language (L1) and L2 (YILDIZ, 2005). In Brazil, a few studies have been conducted on the production of word-initial $/ \sigma /$-clusters (e.g., CORNELIAN, 2003; BONILHA; VINHAS, 2005; RAUBER, 2006; REBELLO; BAPTISTA, 2006). These studies found that the $/ \sigma /$ in $/ \sigma /$-stop clusters are frequently produced with an epenthetic vowel and the $/ \sigma /$ in $/ \sigma /$-sonorant clusters are produced with an epenthetic vowel and voiced. In Brazilian Portuguese (BP), these processes are found in loanwords, as for instance, stress (/ $\sigma /$-stop) which is

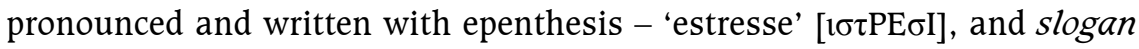

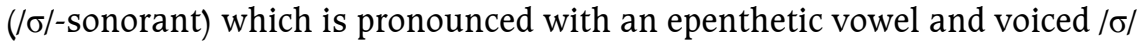
- [I $\zeta \lambda \circ \gamma \alpha]$. Depending on idiolect, palatalization of $/ \sigma /$ is frequent; so that, stress may be pronounced as $[I \Sigma \tau \mathrm{PE} \Sigma]$ and slogan as [IZ $\lambda \mathrm{o} \gamma \alpha]$. Misperception along with transfer and articulatory constraints may influence the production of word-initial $/ \sigma /$-clusters by BP learners of English.

\section{L2 ACQUISITION OF WORD-INITIAL/S/-CLUSTERS}

Consonant clusters are difficult in L1 acquisition and $/ \sigma /$-clusters are the latest clusters to be acquired in English (e.g., MCLEOD; BLEILE, 2003; YILDIZ, 2005). Also, according to the hierarchies presented in McLeod and Bleile (2003), English speaking children acquire three-member clusters after two-member clusters. Studies reviewed by McLeod and Bleile show the following order of acquisition: (1) $/ \sigma \tau /$ and $/ \tau \sigma /$ are the first $/ \sigma /$-clusters to be acquired around the age of three; (2) $/ \sigma v /$ and $/ \sigma \lambda /$ are present in the inventory of children around three years and three months; (3) / $\sigma \mu /$ and $/ \sigma \kappa /$ are acquired around the age of four; (4) three-member clusters $(/ \sigma \mathrm{CC} /)$ appear on the phonological inventory of children over six years.

The acquisition of $/ \sigma /$-clusters by learners of English as an $\mathrm{L} 2$ is even more difficult than it is in L1. BP learners of English tend to turn word-initial $/ \sigma \mathrm{C}(\mathrm{C}) /$ into the $\mathrm{BP}$ permitted initial sequence $/ \mathrm{V} \sigma \mathrm{C}(\mathrm{C}) /$ probably because adults' cross-language speech perception is influenced by L1 pho- 
notactics $^{1}$ (FLEGE, 1989; HALLÉ et al, 1998; SEBASTIAN-GALLÉS, 2005). $\mathrm{BP}$ does not present $/ \sigma / \mathrm{consonantal}$ clusters whereas English presents both initial and final $/ \sigma /$ clusters.

Also, transfer of the BP process of voicing assimilation to the following sound, which turns $/ \sigma /+$ sonorant sequences into $/ \zeta /+$ sonorant $^{2}$, is common, and non-native perception is thought to be influenced by L1 coarticulatory patterns (BEDDOR; HARNSBERGER; LINDEMANN, 2002). Finally, non-native perception is influenced by allophonic or other phonetic variations (HARNSBERGER, 2000, 2001) and thus palatalization may occur. In this case, the cluster may be subjected to the processes of voicing, palatalization and epenthesis. Most L2 learners fail to acquire this structure even after years of instruction and/or experience with the target language.

One of the first studies investigating the acquisition of word-initial $/ \sigma /$-clusters by second language learners was carried out by Carlisle (1991). The participants of Carlisle's (1991, 1992, 1997, 1998, 2006) studies were Spanish learners of English. Carlisle found that prothesis was a common syllable simplification strategy adopted by Spanish speakers when aiming at the production of $/ \sigma /$-clusters. The author also found that clusters in violation of the sonority sequencing principle (SSP) $(/ \sigma /+$ plosive) were more frequently mispronounced than clusters not in violation of the SSP $(/ \sigma /+$ sonorant). The procedure adopted in the data-gathering was the recording of topically unrelated sentences containing the target structure with samples of different preceding phonological contexts. Carlisle (1997) also compared the production of $/ \sigma \mathrm{C} /$ and $/ \sigma \mathrm{CC} /$ in order to investigate markedness relations in terms of cluster length. Overall, his findings revealed that preceding consonants triggered vowel epenthesis more frequently than vowels did, and that three-member $/ \sigma /$-clusters $(/ \sigma \mathrm{CC} /)$ were more susceptible to modification than two-member $/ \sigma /$-clusters $(/ \sigma \mathrm{C} /)$.

Rebello (1997) replicated Carlisle's studies with Brazilian learners of English and found that, besides producing prothesis, Brazilians would transfer voicing to the production of word-initial $/ \sigma /$-clusters. This additional error caused a higher frequency of errors in the production of $/ \sigma /+$ sonorant than in the production of the illegal $/ \sigma /+$ plosive. Six Brazilians learners of English were tested in the production of $/ \sigma \pi, \sigma \tau, \sigma \kappa, \sigma \mu, \sigma \nu, \sigma \lambda$, $\sigma \pi \rho, \sigma \tau \rho, \sigma \kappa \rho, \sigma \pi \lambda, \sigma \kappa \omega /$ in the phonological context of vowels, consonants

(1998).

1 For a comparison between English and Brazilian Portuguese phonotactics, see Souza

2 For instance: the $/ \sigma /$ at the end of casas - 'houses' - in casas amarelas - 'yellow houses' - is pronounced as / // because the following sound is voiced; whereas, the $/ \sigma /$ at the end of casas in casas pretas - 'black houses' - is pronounced as $/ \sigma /$ because the following sound is voiceless. In English the final ' $\mathrm{s}$ ' assumes the voicing status of the preceding ponological context. 
and silence. Silence was found to be the context where prothesis was most frequent followed by vowels and then consonants. The length of the cluster did not seem to play an important role concerning prothesis, even though it showed a tendency contrary to the results of Carlisle (1997) and those of Abrahamsson (1997, 1999), with two-member clusters being slightly more susceptible to prothesis than three-member clusters.

The data from Rebello (1997) were reanalyzed in Rebello and Baptista (2006). The authors divided the preceding environments tested into four categories - sentence initial, pause, vowel, and consonant, whereas Rebello had not considered the occurrence of pauses. By comparing the four types of environment, a significant greater number of errors were found after a pause than after a non-pause environment. The authors suggest that the highest error rate in the context of a pause indicates that fluency difficulties may lead learners to "fall back on native-language syllable structure" (p. 149). Also, Rebello and Baptista argue that it is likely that Carlisle found more errors in the context of consonants than vowels because he did not control for vowel tenseness as did Rebello and Baptista by selecting only tense vowels. They explain that an unstressed reduced vowel (e.g., the start) is a likely candidate for resyllabification and the same is not true for a stressed vowel (e.g., low start).

In order to verify the inconsistencies between Carlisle's and Rebello's findings, Rauber (2002) investigated the production of both Spanish and Portuguese speakers who were learners of English, using the same corpus and method for both native language groups. Nine Argentinean and ten Brazilian undergraduate students of Letras participated in the study. Rauber's results corroborated both Carlisle's and Rebello's studies, showing that difficulty according to cluster type depended on the learner's L1, with $/ \sigma /+$ plosive being the most difficult cluster for Spanish speakers and $/ \sigma /+$ sonorant being the most difficult one for Brazilian Portuguese speakers, even though the difference was not statistically significant for the Brazilian group. Concerning context difficulty, Rauber's study found a different order of difficulty for Brazilians, with vowels being more problematic than consonants and then silence. Concerning cluster length, three-member clusters were more difficult for both Spanish and Portuguese speakers.

Cornelian (2003) carried out a partial replication of Rebello (1997) and Rauber (2002). Twenty Brazilian learners of English recorded a list of sentences containing word-initial $/ \sigma /$-clusters preceded by vowels and consonants. The aim of the study was to investigate the inconsistencies between Rebello's and Rauber's studies. Length of cluster did not seem to be an important factor concerning difficulty, as in Rebello and, $/ \sigma /+$ sonorant clusters were more frequently modified than $/ \sigma /+$ plosive sequences. Vowels were 
shown to cause more prothesis than consonants and an additional finding was that voiced phonological contexts triggered more mispronunciations than their voiceless counterparts.

To sum up, $/ \sigma \mathrm{C}(\mathrm{C}) /$ comprises a complex structure, and; thus, may be difficult to be acquired by both L1 and L2 learners (YILDIZ, 2005). Research on production of word-initial / $\sigma /$-clusters by Brazilian learners of English (REBELLO, 1997; RAUBER, 2002; SILVEIRA, 2002; CORNELIAN, 2003; REBELLO; BAPTISTA, 2006; RAUBER, 2006) has shown that (1) Brazilian Portuguese phonotactics do not allow word-initial $/ \sigma /$-clusters causing learners to turn $/ \sigma \mathrm{C}(\mathrm{C}) /$ into $/ \mathrm{V} \sigma \mathrm{C}(\mathrm{C}) /$; also, (2) the Brazilian Portuguese process of voicing assimilation to the following sound tends to make learners produce $/ \zeta /+$ sonorant instead of $/ \sigma /+$ sonorant.

Different studies have provided different hierarchies of difficulty in production of word-initial $/ \sigma \mathrm{C}(\mathrm{C}) /$. Table 1 displays the hierarchies of difficulty concerning preceding phonological environment and cluster type for BP learners.

Table 1 - Hierarchies of difficulty of environment and cluster type from the easiest to the most difficult.

\begin{tabular}{|c|c|c|c|c|c|}
\hline & $\begin{array}{l}\text { Silveira } \\
\text { (2002) }\end{array}$ & $\begin{array}{c}\text { Rauber (2002, } \\
\text { 2006) }\end{array}$ & $\begin{array}{c}\text { Cornelian } \\
\text { (2003) }\end{array}$ & $\begin{array}{c}\text { Rebello \& } \\
\text { Baptista } \\
\text { (2006) }\end{array}$ & $\begin{array}{c}\text { Bettoni \& } \\
\text { Koerich } \\
\text { (2009) }\end{array}$ \\
\hline Cluster type & $\begin{array}{r}\sigma \tau \rho>\sigma \kappa> \\
\sigma \kappa \rho>\sigma \pi \rho \\
>\sigma \lambda>\sigma \tau \\
>\sigma \pi>\sigma V\end{array}$ & $\begin{array}{c}/ \sigma /+ \text { stop }> \\
/ \sigma /+ \text { stop }+/ \mathrm{L} / \\
>/ \sigma \lambda />/ \sigma \mathrm{N} /\end{array}$ & $\begin{array}{l}/ \sigma /+ \text { stop }> \\
/ \sigma \lambda />/ \sigma \mathrm{N} /\end{array}$ & $\begin{array}{c}\sigma \pi \rho, \sigma \pi \lambda, \\
\sigma \tau \rho, \sigma \kappa \omega, \\
\sigma \kappa \rho>\sigma \tau, \\
\sigma \kappa, \sigma \pi> \\
\sigma \mu, \sigma \nu, \sigma \lambda\end{array}$ & $\begin{array}{c}\sigma \nu>\sigma \tau \\
>\sigma \kappa, \sigma \kappa \rho \\
>\sigma \pi> \\
\sigma \mu>\sigma \lambda \\
>\sigma \pi \rho\end{array}$ \\
\hline $\begin{array}{l}\text { Phonological } \\
\text { environment }\end{array}$ & - & null $>\mathrm{C}>\mathrm{V}$ & $\mathrm{C}>\mathrm{V}$ & $\begin{array}{l}\mathrm{C}, \text { initial }> \\
\mathrm{V}>\text { pause }\end{array}$ & $\begin{array}{c}\text { Silence }> \\
\quad \mathrm{C}>\mathrm{V}\end{array}$ \\
\hline
\end{tabular}

Silveira (2002) found a positive correlation between perception and production of word-initial $/ \sigma /$-clusters indicating that production errors may be caused by misperception. If misperception is one of the triggers of misproduction, modifying learners' perception may have an effect on learners' production. Bettoni and Koerich (2009), the first study investigating effects of perceptual training on the pronunciation of $/ \sigma /$-clusters in BP/English interphonology, showed that an identification perceptual training program can actually help learners improve their perception of word-initial $/ \sigma /$-clusters and generalize the improvement to unfamiliar talkers and untrained $/ \sigma \mathrm{C} /$ and $/ \sigma \mathrm{CC} /$. Results also revealed transfer of improvement to production of word-initial $/ \sigma /$-clusters and retention of improvement in perception and production after five months. 
Thus, in line with the studies mentioned above, the present study investigated the production and perception of word-initial $/ \sigma /$-clusters. The difference lies in the more controlled phonological context, a larger number of participants, and an investigation in both perception and production as well as the relationship between both domains.

\section{Method}

\subsection{ObJeCtive, RESEARCH QUESTION, AND HyPOTHESES}

The present study aimed at investigating different error rates in production and perception of $/ \sigma \mathrm{C}(\mathrm{C}) /$ according to phonological context and cluster type.

Research Question: Is the production and the perception of word-initial $/ \sigma /$-clusters influenced by phonological context and/or cluster type? Hypotheses 1 and 2 refer to production and hypotheses 3 and 4 refer to perception. Hypothesis 5 refers to the relationship between perception and production.

Hypothesis 1: The following hierarchy of difficulty is proposed for production, from the most difficult to the easiest context: vowels > voiced consonants $>$ voiceless consonants $>$ silence.

Background: Cornelian (2003), Rauber (2002, 2006), Bettoni; Koerich (2009). Hypothesis 2: The following hierarchy of difficulty is proposed for production, from the most difficult to the easiest cluster-type: $/ \sigma /+$ sonorant $>/ \sigma /+$ stop $>/ \sigma \mathrm{C}(\mathrm{C}) /$.

Background: Rebello; Baptista (2006).

Hypothesis 3: The following hierarchy of difficulty is proposed for perception, from the most difficult to the easiest context: vowels > voiced consonants $>$ voiceless consonants $>$ silence.

Background: Cornelian (2003), Rauber (2002, 2006), Bettoni; Koerich (2009) (based on the existence of a relationship between perception and production, the hierarchy found for production in these studies was proposed for perception here).

Hypothesis 4: The following hierarchy of difficulty is proposed for perception, from the most difficult to the easiest cluster type: $/ \sigma /+$ sonorant $>/ \sigma /+$ stop. Background: Rebello; Baptista (2006) (based on the existence of a relationship between perception and production, the hierarchy found for production in this study was proposed for perception here).

Hypothesis 5: There will be a positive correlation between identification and production of word-initial /s/-clusters.

Background: Silveira (2002). 


\subsection{PARTICIPANTS}

The participants were 23 Brazilian learners of English with at least 200 hours of previous formal instruction in English. 15 participants were females and eight were males. The age range was 9 to 55 - five aged between 9 and 16, fifteen aged between 18 and 35, and three aged between 50 and 55. The youngest participant (P1) was a female with six years of eight hours of formal instruction per week. She was fluent in English and used English out of school in a frequent regular basis, but had never lived in an English-speaking country and was not bilingual. Her proficiency level was similar to other participants' as well as her amount of exposure to spoken English. Thus, irrespective of her young age, she was a suitable participant.

\subsection{DATA-GATHERING INSTRUMENTS}

As detailed below, five instruments were used for data gathering and analysis of the hypotheses proposed. They were administered in the following order: one questionnaire, three production tests, and a perception test. Participants were instructed in BP in order to ensure comprehension and short intervals were given after each test, and each session lasted from 45 to 60 minutes.

\subsubsection{BACKGROUND QuestionNAIRE}

The background questionnaire aimed at assessing biographical information which was thought to be possible of influencing the results obtained in the study. Among the data gathered in the questionnaire were age, sex, amount of exposure to English, and knowledge of other languages.

\subsubsection{TEXT-READING TESTS}

Two text-reading tests were administered aiming at eliciting production of $/ \sigma /$-clusters. The first text was a paragraph prepared for testing ESL/EFL learners' pronunciation (http://accent.gmu.edu/pdfs/elicitation.pdf). It contained ten tokens of word-initial $/ \sigma /$-clusters $(/ \sigma \pi, \sigma \tau, \sigma \kappa, \sigma \mu, \sigma v, \sigma \lambda)$ . The second text was The story of Sleeping Beauty (http://www.bbc.co.uk/ education/wordsandFigures), originally prepared for native English speaking children practice word-initial $/ \sigma /$-clusters. It contains sixteen tokens of word-initial / $\sigma /$-clusters $(/ \sigma \pi, \sigma \tau, \sigma \mu, \sigma \nu, \sigma \lambda, \sigma \pi \rho /)$.

\subsubsection{Phrase-REAding Test}

A phrase-reading test was used to assess production in controlled phonological contexts. The clusters included were (a) $/ \sigma \lambda /$ - represented by the words 'slow' and 'slap'; (b) / $\sigma \mu /$ - represented by the words 'small' and 'smi- 
les'; (c) / $\sigma v /$ - represented by the words 'snow' and 'snail'; (d) / $\sigma \kappa /$ - represented by the word 'scan'; (e) $/ \sigma \pi /$ - represented by the words 'speak' and 'sport'; (f) $/ \sigma \tau /$ - represented by the words 'stop' and 'stone'; (g) / $\sigma \kappa \rho /$ - represented by the word 'scream'; and (h) / $\sigma \pi \rho /$ - represented by the word 'spring'. Four preceding phonological contexts were tested (a) a vocalic context $-/ \alpha \mathrm{Y} /$ as in 'how smiles'; (b) a voiceless consonant - / $\phi /$ as in 'if smiles'; (c) a voiced consonant - $/ \phi$ / as in 'move smiles'; and (d) silence as in 'smiles'. The total of tokens was 45 per participant.

\subsubsection{Perceptual identification test}

The perception test was a two-alternative forced-choice identification test. The contrasts tested were $[\sigma \mathrm{C}-1 \sigma \mathrm{C}, \sigma \mathrm{C}-1 \zeta \mathrm{C}, \sigma \mathrm{C}-\zeta \mathrm{C}]$ and the $/ \sigma /$-clusters tested were $[\sigma \tau, \sigma \pi, \sigma \kappa, \sigma \lambda, \sigma \mu, \sigma v]$; therefore, there were twelve minimal pairs $[\sigma \tau-1 \sigma \tau, \sigma \pi-1 \sigma \pi, \sigma \kappa-1 \sigma \kappa, \sigma \lambda-1 \sigma \kappa, \sigma \lambda-\zeta \gamma, \sigma \lambda-1 \zeta \lambda, \sigma \mu-1 \sigma \mu, \sigma \mu-\zeta \mu, \sigma \mu-$ $1 \zeta \mu, \sigma v-1 \sigma v, \sigma v-\zeta v, \sigma v-1 \zeta v]$. There were four preceding contexts: a voiced consonant as in 'move', a voiceless consonant as in 'if', a vowel-like sound as in 'how', and silence. Some examples of minimal pairs in the test are: 'if smiles' vs. 'iffy smiles'; and, 'how's nail' vs. 'how snail'.

The stimulus was recorded by three native speakers of American English and the test was assembled by the researcher using the software for sound editing Audacity 2.0.2. The intervals between trials were four seconds long and all talkers were asked to produce the phrases with the same intonation. Participants listened to a single stimulus, read two phrases in an answer sheet, and had to identify the stimulus heard with one of the phrases. The total number of tokens was 80 . Participants were told beforehand that in the beginning of the test there were three trials which would be discarded and served as training and adaptation.

\subsection{Data Analysis}

Production was perceptually analyzed by the researcher, and acoustically analyzed using Praat 4.3.12 software. With the aid of spectrograms, the productions of $/ \sigma \mathrm{C}(\mathrm{C}) /$ were categorized as $/ \sigma \mathrm{C}(\mathrm{C}) /, / \mathrm{V} \sigma \mathrm{C}(\mathrm{C}) /, / \zeta \mathrm{C}(\mathrm{C}) /$ or $/$ $\mathrm{V} \zeta \mathrm{C}(\mathrm{C}) /$. Formants were read and measured in order to identify the presence of a vowel and of voicing or palatalization of the $/ \sigma /$.

Perception data were analyzed according to number of correct answers in the identification test as well as according to each contrast - I $\sigma \mathrm{C}-1 \sigma \mathrm{C}, \sigma \mathrm{C}-\zeta \mathrm{C}, \sigma \mathrm{C}-1 \zeta \mathrm{C} /$.

The data received statistical treatment using the Statistical Package for Social Studies (SPSS) software. Kruskal-Wallis tests and Mann-Whitney tests were used to investigate effects of nominal variables on differences since the data were not normally distributed. Pearson and Spearman Tests were used to verify correlations. 


\section{Results And Discussion}

The investigation concerned the perception and production of word-initial $/ \sigma /$-clusters in $\mathrm{BP} /$ English interphonology in relation to two variables previously tested in the production domain by Rauber $(2002,2006)$, Silveira (2002), Cornelian (2003), and Rebello and Baptista (2006), namely - phonological context and cluster type. And in the perception domain by Silveira (2002), namely - cluster type. The influence of phonological context had not been tested in the perception domain considering word-initial $/ \sigma /$-clusters.

Two hypotheses were investigated concerning production, two were investigated concerning perception, and one was investigated concerning the relationship between perception and production. The production hypotheses are discussed below followed by the perception hypotheses. Finally, the hypothesis on the relationship between perception and production is discussed.

4.1 Production of WORD-INITIAL / $\sigma /$-CLUSTERS AND PHONOLOGICAL CONTEXT - Hypothesis 1

Following Cornelian (2003), the first hypothesis stated that 'vowels' would trigger more errors than 'consonants', which would trigger more errors than 'silence' preceding $/ \sigma C(C) /$, and that 'voiced consonants' ( $+v d C)$ would trigger more errors than their 'voiceless counterparts' (-vdC). Thus, from the most difficult to the easiest context, the following hierarchy was proposed: $\mathrm{V}<+\mathrm{vd} \mathrm{C}<-\operatorname{vd~C}<$ silence.

The mean accuracy in the production task was $65 \%$. Thus, many errors occurred. Table 2 displays the rate and raw scores of misproductions by phonological context.

Table 2 - Production by preceding phonological context

\begin{tabular}{lrrr}
\hline Context & $\mathbf{N}$ & Raw Score & Accuracy Rate \\
Vowel & 483 & 275 & $57 \%$ \\
Silence & 161 & 98 & $61 \%$ \\
Voiced consonant & 552 & 372 & $67 \%$ \\
Voiceless consonant & 437 & 317 & $72 \%$ \\
TOTAL & 1633 & 1062 & $65 \%$ \\
\hline
\end{tabular}

The following hierarchy of difficulty was found concerning the effect of phonological context, from the most difficult to the easiest: vowels $(57 \%)<$ silence $(61 \%)<$ voiced consonant $(67 \%)<$ voiceless consonants $(72 \%)$. The coincidences with the hierarchy proposed in the hypothesis are that vowels actually triggered more misproductions than the other contexts 
and that voiced consonants caused more errors than voiceless consonants. Silence, on the other hand, was found to be much more problematic than expected. In order to investigate whether the differences found were significant, statistical tests were run on the data of the twenty-three participants.

A Kruskall-Wallis Test yielded a non-significant result for context effect $\left(\mathrm{x}^{2}=4.066, \mathrm{p}=.254\right)$. Against the predictions of the hypothesis, the results indicated that there was no significant effect of phonological context on the rate of mispronunciations.

4.2 Production of WORd-INitial / $\sigma /$-Clusters AND ClUSter TYPE HyPothesis 2

Hypothesis 2 stated that $/ \sigma /+$ sonorant clusters would be more frequently modified than $/ \sigma /+$ stop clusters. Also among the $/ \sigma /+$ stop clusters, two-member clusters would be more frequently modified than three-member clusters.

Table 3 displays the data obtained for production by cluster type. Table 3 - Results in production by cluster type

\begin{tabular}{lrrr}
\hline & $N$ & Raw Score & Accuracy rate \\
$/ \sigma \tau /$ & 276 & 244 & $88 \%$ \\
$/ \sigma \pi /$ & 299 & 244 & $82 \%$ \\
$/ \sigma \kappa /$ & 92 & 68 & $74 \%$ \\
$/ \sigma /+$ stop & 667 & 556 & $83 \%$ \\
$/ \sigma \kappa \mathrm{P} /$ & 92 & 77 & $84 \%$ \\
$/ \sigma \pi \mathrm{P} /$ & 92 & 79 & $86 \%$ \\
$/ \sigma \mathrm{CC} /$ & 184 & 156 & $85 \%$ \\
$/ \sigma \mu /$ & 230 & 85 & $37 \%$ \\
$/ \sigma \nu /$ & 299 & 137 & $46 \%$ \\
$/ \sigma \lambda /$ & 253 & 128 & $51 \%$ \\
$/ \sigma /+$ sonorant & 782 & 350 & $45 \%$ \\
TOTAL & 1633 & 1062 & $65 \%$ \\
\hline
\end{tabular}

The results shown on the table seem to indicate that there was no effect of cluster length on production, and that $/ \sigma /+$ sonorant clusters were more difficult to be pronounced than $/ \sigma /+$ stop clusters. In order to verify whether the differences were significant, Mann-Whitney Tests were run on the data. The Mann-Whitney Test run on $/ \sigma \mathrm{C} /$ and $/ \sigma \mathrm{CC} /$ clusters confirmed that cluster length did not affect the results, $Z=.111, p=.928$, and the Mann-Whitney Test run on $/ \sigma \mathrm{C} / \mathrm{vs} . / \sigma /+$ sonorant yielded a significant result, $\mathrm{Z}=6.953, \mathrm{p}=.000$, showing that $/ \sigma /+$ sonorant clusters were significantly 
more difficult to be produced than $/ \sigma /+$ stop clusters. Thus, Hypothesis 2 was partially corroborated.

Considering type of misproduction, even though voicing tends to affect only $/ \sigma /+$ sonorant clusters and prothesis tends to affect all cluster types, voicing was three times more frequent than prothesis. The occurrence of prothesis combined with voicing was also larger than of prothesis alone.

4.3 PERCEPTION OF WORD-INITIAL / $\sigma /$-CLUSTERS AND PHONOLOGICAL CONTEXT - HyPOTHESIS 3

Based on the premise that there is a relationship between perception and production, the hierarchy of difficulty found for production in previous studies was proposed for perception, in the line of hypothesis $\mathrm{H} 1$ above: $\mathrm{V}>+\mathrm{vd} \mathrm{C}>-\mathrm{vd} \mathrm{C}>$ silence. The data obtained from the identification test were used. The results obtained in the identification test by context are displayed in Table 4.

Table 4 - Results for identification by phonological context

\begin{tabular}{lrrr}
\hline Context & $\boldsymbol{N}$ & Raw Score & Accuracy Rate \\
Silence & 138 & 125 & $90.57 \%$ \\
Vowel & 552 & 435 & $78.80 \%$ \\
Voiced consonant & 736 & 565 & $76.76 \%$ \\
Voiceless consonant & 414 & 355 & $85.74 \%$ \\
TOTAL & 1840 & $\mathbf{1 4 8 0}$ & $\mathbf{8 0 . 4 3 \%}$ \\
\hline
\end{tabular}

Even though the results pointed to silence and voiceless consonants as easier phonological contexts regarding perception, a Kruskal-Wallis Test failed to yield significance, $\mathrm{x}^{2}=6.157, \mathrm{p}=.104$. Hypothesis 3 was not confirmed, but results showed a tendency towards it.

\subsection{Perception of WORD-INITIAL / $\sigma /$-CLUSTERS AND CLUSTER TYPE - HYPOTHESIS 4}

Hypothesis 4 was based on the results of Silveira (2002) who found a tendency for correlation between perception and production concerning cluster type. The hierarchy proposed for production was proposed for perception, from the most difficult to the easiest: $/ \sigma /+$ sonorant $>/ \sigma /+$ stop. Table 5 displays the results obtained in the identification by cluster type. 
Table 5 - Identification by cluster type

\begin{tabular}{lrrr}
\hline & & & IDENTIFICATION \\
$/ \sigma \tau /$ & $\mathbf{N}$ & Raw Score & Accuracy rate \\
$/ \sigma \pi /$ & 138 & 123 & $89.13 \%$ \\
$/ \sigma \kappa /$ & 138 & 118 & $85.50 \%$ \\
$/ \sigma /+$ stop & 138 & 118 & $85.50 \%$ \\
$/ \sigma \mu /$ & 414 & 359 & $86.71 \%$ \\
$/ \sigma \nu /$ & 414 & 324 & $78.26 \%$ \\
$/ \sigma \lambda /$ & 414 & 328 & $79.22 \%$ \\
$/ \sigma /+$ sonorant & 598 & 469 & $78.42 \%$ \\
TOTAL & 1426 & 1121 & $78.61 \%$ \\
\hline
\end{tabular}

A Mann-Whitney Test failed to yield significance, $Z=1.859$, $p$ $=.063$. However, there is a tendency towards the hypothesis and significance $(p<.05)$ was almost reached.

\subsection{THE RELATIONSHIP BETWEEN PRODUCTION AND IDENTIFICATION - HYPOTHESIS 5}

Hypothesis 5 proposed that there would be a relationship between identification and production of word-initial $/ \sigma /$-clusters.

A Pearson test run on the data of identification and production accuracy rates yielded a positive correlation, $\mathrm{r}(22)=.864$, significant at the .001 level $(p=.000)$. A Spearman's Rank Order Correlation test also yielded a positive and significant result - rho $(22)=.762$. Figure 1 illustrates the relationship between identification and production showing that the better the performance of a participant in the identification test the higher the number of accurate word-initial $/ \sigma /$-clusters production by that participant. Figure 1-Correlation between production and identification

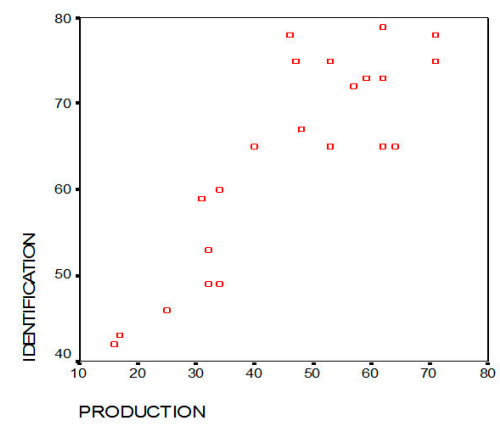


The identification test assessed the clusters tested in the phrase-reading test in the same phonological contexts they were presented there. Table 6 displays the raw scores and rates in the identification test and in the phrase-reading test by cluster.

Table 6 - Identification test and phrase-reading test by cluster

\begin{tabular}{l|l|llll|lll}
\hline \multicolumn{1}{c}{} & \multicolumn{9}{c}{ Identification } & \multicolumn{3}{c}{ Production } \\
\hline & Rank & $\mathrm{N}$ & Score & Rate & Rank & $\mathrm{N}$ & Score & Rate \\
$/ \sigma \mu /$ smile & 6 & 414 & 324 & $78.26 \%$ & 6 & 92 & 34 & $36.96 \%$ \\
$/ \sigma \nu /$ snail & 4 & 414 & 328 & $79.22 \%$ & 5 & 92 & 39 & $42.39 \%$ \\
$/ \sigma \lambda /$ slow & 5 & 598 & 469 & $78.42 \%$ & 4 & 92 & 46 & $50.00 \%$ \\
$/ \sigma /+$ sonorant & & 1426 & 1121 & $78.61 \%$ & & 276 & 119 & $43.11 \%$ \\
$/ \sigma \pi /$ sport & 1 & 138 & 123 & $89.13 \%$ & 1 & 69 & 55 & $79.71 \%$ \\
$/ \sigma \tau /$ stop & 2 & 138 & 118 & $85.50 \%$ & 1 & 69 & 55 & $79.71 \%$ \\
$/ \sigma \kappa /$ scan & 2 & 138 & 118 & $85.50 \%$ & 3 & 69 & 46 & $66.67 \%$ \\
$/ \sigma /+$ stop & & 414 & 359 & $86.71 \%$ & & 207 & 156 & $75.36 \%$ \\
\hline MEAN & & 1840 & 1480 & $80.43 \%$ & 483 & 275 & $56.93 \%$ \\
\hline
\end{tabular}

Correlation tests confirmed the relationship that can be inferred from Table 6. A Pearson Correlation Test yielded a significant result, $\mathrm{r}(20)$ $=.720, \mathrm{p}=.000$, and a Spearman's Rank Order Correlation also yielded a significant result, $\mathrm{rho}(20)=.668, \mathrm{p}=.001$. Thus, Hypothesis 5 was corroborated regarding cluster type as well as accurracy rates in general.

\subsection{SUMMARY AND FURTHER DISCUSSION ABOUT THE RESULTS}

This research was motivated by conflicting results of studies in Brazilian Portuguese/English interphonology about the influence of preceding phonological context and cluster type in the production of word-initial

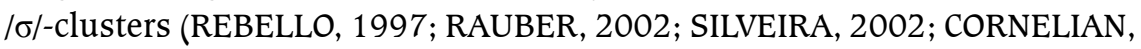
2003; RAUBER, 2006; REBELLO; BAPTISTA, 2006), and the lack of studies investigating such influence on perception. Differently from previous studies (e.g., RAUBER, 2006; REBELLO; BAPTISTA, 2006), preceding phonological context did not significantly affect the production of word-initial $/ \sigma /$-clusters $(\mathrm{x} 2=4.066, \mathrm{p}=.254)$, thus Hypothesis 1 was refuted. There was a tendency, however, for vowels to be the most difficult context and for voiced consonants to be more difficult than their voiceless counterparts, as in Cornelian (2003). The following hierarchy of difficulty was found from the most difficult to the easiest: Vowels $(57 \%)>$ silence $(61 \%)>$ voiced consonants $(67 \%)>$ voiceless consonants $(72 \%)$. 
The clusters in violation of the sonority sequencing principle ${ }^{3}$ $(/ \sigma /+$ stop clusters) were the clusters with the smallest number of misproductions $(/ \sigma /+$ sonorants - accuracy rate of $45 \%$ vs. $/ \sigma /+$ stops - accuracy rate of $84 \% ; Z=6.953, p=.000$ ), thus, as in Cornelian (2003) $-/ \sigma /+$ sonorants were more difficult than $/ \sigma /+$ stops. Thus, L1 transfer seemed to affect L2 pronunciation more than universal principles ${ }^{4}$. No significant difference was found for cluster length, though $(/ \sigma \mathrm{C} /$ - accuracy rate of $83 \%$; $/ \sigma \mathrm{CC} /$ - accuracy rate of $85 \%$ ). Hypothesis 2 , thus, was only partially corroborated and the results followed the same tendency found in Cornelian (2003) - / $/++$ sonorants (accuracy rate of $45 \%$ ) were more difficult than $/ \sigma /+$ stops.

Regarding effects of phonological context on perception, a tendency for vowels and voiced consonants to be the most difficult contexts was found, but failed to yield statistical significance $\left(\mathrm{x}^{2}=6.157, \mathrm{p}=.104\right)$. The accuracy rate tendency found was voiced consonant $(76.76 \%)<$ vowel $(78.80 \%)<$ voiceless consonants $(85.84 \%)<$ silence $(90.57 \%)$. Thus, preceding phonological context did not significantly affect perception either, and Hypothesis 3 was refuted. The position of 'silence' in the hierarchy was the greatest contrast between perception and production - it was the easiest phonological context in perception and the second most difficult phonological context in production. Voiceless consonants, on the other hand, were among the easiest contexts in both domains.

The hierarchy proposed in Hypothesis 4 was that $/ \sigma /+$ sonorant vs. modified $/ \sigma /+$ sonorant clusters (e.g., $/ \sigma \lambda \lambda_{1} /$ vs. $/ \imath \zeta \lambda i \pi /$ ) were more difficult to discriminate than $/ \sigma /+$ stop vs. modified $/ \sigma /+$ stop clusters (e.g., $/ \sigma \lambda \iota \kappa /$ vs. / $1 \sigma \pi(\kappa /)$. The same hierarchy was found in the present study, but statistical tests failed to reach significance $(\mathrm{Z}=1.859, \mathrm{p}=.063)$. Hypothesis 4 was not corroborated, but a tendency towards it was found. Thus, $/ \sigma /+$ sonorant clusters were more difficult than $/ \sigma /+$ stop clusters in perception as well as in production ( $\mathrm{H} 2)$.

Hypothesis 5 investigated whether there was a relationship between perception and production of word-initial/s/-clusters regarding cluster type and overall accuracy rate. Statistical tests yielded significant correlations between identification and the production in the reading tests $(\mathrm{r}(22)=.864$,

3 Following the Sonority Sequencing Principle (SSP), Roca (1994) establishes that "the sonority profile of the syllable must slope outwards from the peak" (p.153). Words such skin and tiks are possible syllables in English, but they are in violation of the SSP since $/ \sigma /$ is more sonorant than $/ \kappa /$. Clements (1990) states that clusters conforming to the SSP are the most frequent; however, not the only possibilities, and that violations to the SSP happen in syllable boundaries because in the underlying representation, the boundaries may be extrassyllabic and an epenthetic vowel may be represented.

4 Bettoni-Techio (2005) found a similar result when investigating production of final alveolar stops in BP/English Interphonology. 
$\mathrm{p}=.000$ ). The correlations found indicated that around $60 \%$ of what happened in production was related to perception. Identification and production also correlated considering cluster type $(\mathrm{r}(20)=.720, \mathrm{p}=.000)$. Thus, Hypothesis 5 was corroborated. In perception and production, $/ \sigma /+$ sonorant clusters were more difficult than $/ \sigma /+$ stop clusters, but the correlation was weaker than when it was based on participants - around 45\%. Silveira (2002) also found a positive correlation between perception and production considering cluster type. The study assessed production through an oral translation task and perception through a discrimination test.

To sum up, contrary to previous findings, preceding phonological context does not seem to affect perception and production of $/ \sigma /$-clusters. Cluster type, on the other hand, tends to affect both abilities. In this study, $/ \sigma /+$ sonorant clusters were found to be more difficult than $/ \sigma /+$ stop clusters in both domains. These similarities may be taken as an indication of the existence of a unified mechanism for perception and production in that both domains are affected by the same variables and to a similar extent. The significant correlations found between perception and production reinforce this conclusion.

\section{FinAL REMARKS}

The present study investigated the effects of preceding phonological

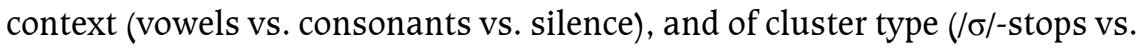
$/ \sigma /$-sonorants) on the perception and production of word-initial $/ \sigma /$-clusters, and the effects of length $(/ \sigma \mathrm{C} / \mathrm{vs} . / \sigma \mathrm{CC} /)$ on the production of these clusters. The number of participants tested was greater than in previous studies, the data-gathering instruments provided more controlled phonological contexts, and effects of preceding phonological context on perception of word-initial $/ \sigma /$-clusters were investigated for the first time.

Preceding phonological context did not significantly affect error rate in perception or in production. However, as in Cornelian (2003), a tendency was found for vowels and voiced consonants as preceding contexts of $/ \sigma /$ clusters to be more difficult than voiceless consonants. Also as in Cornelian's study, no significant difference was found for cluster length - participants mispronounced the $/ \sigma \mathrm{C} /$ clusters as frequently as the $/ \sigma \mathrm{CC} /$. On the other hand, regarding the constituents of the clusters, $/ \sigma /+$ sonorant clusters were significantly more difficult than $/ \sigma /+$ stop clusters, both in perception and in production, corroborating Cornelian (2003), Rauber (2002, 2006), and Rebello and Baptista (2006).

The hierarchy of difficulty found in this study is probably specific to BP native speakers since L1 transfer seemed to affect L2 pronunciation more than universal principles. This hierarchy must be taken into account 
when designing pedagogical instruments and classes for BP native speakers so that learning is facilitated. The target structure must be presented to students from the easiest to the most difficult (considering both preceding phonological context and cluster type). Also, the study showed that there is a strong and consistent relationship between perception and production; thus, when designing teaching material, it is important to provide learners with oral perception and production tasks. We expect that when learners focus their attention on word-initial $/ \sigma /$-clusters, they are able to tune their perception to the new structure and transfer this improvement in perception to production (BETTONI; KLUGE, 2014). Likewise, awareness of the accurate production may facilitate the distinction between word-initial $/ \sigma /$-clusters in phrases and their minimal pairs both in perception and in production helping learners to form new sound categories.

\section{REFERENCES}

ABRAHAMSSON, Niclas. Vowel epenthesis of initial $/ \mathrm{SC}(\mathrm{C}) /$ cluster in Spanish speakers'L1 and L2 production: puzzle or evidence for natural phonology? In: JAMES, A.; LEATHER, J. (Ed.) New Sounds 97: Proceedings of the Third International Symposium on the Acquisition of Second-language Speech. Klagenfurt: University of Klagenfurt, 1997. p. 8-16.

ABRAHAMSSON, Niclas. Vowel epenthesis of / $\mathrm{SC}(\mathrm{C}) /$ onsets in by Spanish/Swedish interphonology: a longitudinal case study. Language Learning, n. 49, p. 473-508, 1999.

BAPTISTA, Barbara O. Adult phonetic learning of a second language vowel system. In: BAPTISTA, B. O.; WATKINS, M. A. (Eds.). English with a latin beat: Studies in Portuguese/Spanish - English Interphonology. Amsterdam: John Benjamins Publishing, 2006. p.19-40

BEDDOR, Patrice S.; HARNESBERGER, James D.; LINDEMMAN, Stephanie. Language-specific patterns of vowel-to-vowel coarticulation: Acoustic structures and their perceptual correlates. Journal of Phonetics, n. 30, p. 591-627, 2002.

BEST, Catherine. T. A direct realist view of cross-language speech perception. In: STRANGE, W. (Ed.). Speech perception and linguistic experience: Issues in cross-language research. Timonium: York Press, 1995. p. 171-206.

BETTONI, Melissa; KLUGE, Denise C. Encontros consonantais do inglês iniciandos por /s/- Efeitos de um treinamento percepetual. In: BRAWERMAN-ALBINI, A.; GOMES, M. L. de. C. (Orgs.). O jeitinho brasileiro de falar inglês: pesquisas sobre pronúncia do inglês por falantes brasileiros. 1ed. Campinas, SP: Pontes Editores, 2014. p. 105-125.

BETTONI, Melissa; KOERICH, Rosana D. Perceptual training on the pronunciation of /s/-clusters in Brazilian Portuguese/English In: RAUBER, A. S., WATKINS, M.A.; BAPTISTA, B. O. (Eds.). Recent Research in Second Language: Perception and Production, 2009. p. 154-173.

BETTONI-TECHIO, Melissa. Production of final alveolar stops in Brazilian Portuguese/English interphonology. Federal University of Santa Catarina, Florianópolis, 2005. Unpublished master thesis.

BONILHA, Giovana F.; VINHAS, Luciana. I. Aquisição de onsets complexos: militância da hierarquia de restrições da língua materna. Revista Virtual de Estudos da Linguagem - ReVEL, ano 3, n. 5, 2005.

CARLISLE, Robert S. Environment and markedness as interacting constraints on vowel epenthesis. In: 
JAMES, A; LEATHER, J. (Eds.) New Sounds 92: Proceedings of the Third International Symposium on the Acquisition of Second-language Speech. Klagenfurt, Austria: University of Klagenfurt, 1992. p. 64-75.

. Markedness and environment as internal constraints on the variability of interlanguage phonology. In: YAVAS, M. (Ed.). First and second language phonology. San Diego: Singular, 1994. p. 223-249.

Production of English initial /s/-clusters by speakers of Brazilian Portuguese and Argentinean Spanish. In: BAPTISTA, B. O.; WATKINS, M. (Eds.), English with a latin beat. Amsterdam: John Benjamins Publishing, 2006. p. 155-167

. The acquisition of onsets in a markedness relationship: a longitudinal study. Studies in Second Language Acquisition, v. 20, p. 245-260, 1998.

The influence of environment on vowel epenthesis in Spanish/English interphonology. Applied Linguistics, v. 12, n. 1, p. 77-95, 1991.

The modification of onsets in a markedness relationship: Testing the interlanguage structural conformity hypothesis. Language learning, v. 47, p. 327-361, 1997.

CLEMENTS, George Nick. The role of the Sonority Cycle in Core Syllabification. In: KINGSTON, J; BECKMAN, M. (Eds.). Laboratory Phonology 1, Cambridge University Press: Cambridge, 1990.

CORNELIAN, Deunésio. Brazilian Learners' Production of Initial /s/ Clusters: Phonological Structure and Environment. Federal University of Santa Catarina, Florianópolis, 2003. Unpublished master thesis.

FLEGE, James E. Chinese subjects' perception of the word-final English /t/-/d/ contrast: performance before and after training. The Journal of the Acoustical Society of America, n. 86, v. 5, p. 1684-1697, 1989.

. Factors affecting degree of perceived foreign accent in English sentences. Journal of the Acoustical Society of America, n. 84, v. 1, p. 70-79, 1988.

. Second Language speech learning: theory, findings, and problems. In STRANGE, W. (Ed.), Speech Perception and linguistic experience: Issues in cross-language research. Timonium, MD: York Press, 1995. p. 233-272.

HALLÉ, Pierri; SEGUI, Juan; FRAUENFELDER, Uli. H.; MEUNIER, Christine. The processing of illegal consonant clusters: A case of perceptual assimilation? Journal of Experimental Psychology: Human Perception and Performance, v. 24 n. 2, p. 592-608, 1998.

HARNSBERGER, James D. A cross-language study of the identification of non-native nasal consonants varying in place of articulation. Journal of the Acoustical Society of America, v. 108 , p. $764-783,2000$.

On the relationship between identification and discrimination of non-native nasal consonants. Journal of the acoustical society of America, v. 110, n. 1, p. 489-503, 2001.

KOERICH, Rosana D. Perception and production of word-final vowel epenthesis by Brazilian EFL students. Universidade Federal de Santa Catarina, Florianópolis, 2002. Unpublished doctoral dissertation.

MCLEOD, Sharynne; BLEILE, Ken. Neurological and developmental foundations of speech acquisition: A summary - brain development and the environment. In: AMERICAN SPEECH-LANGUAGE-HEARING ASSOCIATION CONVENTION, 2003, Chicago. Proceedings... Disponível em: <http://www.speech-language-therapy.com/pdf/docs/ASHA03McLeodBleile.pdf>. Acesso em: 20 dez. 2015.

RAUBER, Andréia S. S. Production of English initial/s/-clusters by speakers of Brazilian Portuguese and Argentine Spanish. In: BAPTISTA, B. O.; WATKINS, M. A. (Eds.). English with a Latin Beat: Studies in Portuguese/Spanish - English Interphonology, Amsterdam: John Benjamins, 
2006. p. $155-167$.

The Production of English Initial /s/Clusters by Portuguese and Spanish EFL Speakers. Universidade Federal de Santa Catarina, Florianópolis, 2002. Unpublished master thesis.

REBELLO, Jeanne. T. The acquisition of initial/s/-clusters by Brazilian EFL learners. In: LEATHER, J.; JAMES, A. (Eds.) New Sounds 97: Proceedings of the third international symposium on the acquisition of second-language speech. Klagenfurt: University of Klagenfurt, 1997. p. 336-350.

REBELLO, Jeanne. T.; BAPTISTA, Barbara. O. The influence of voicing on the production initial /s/-clusters by Brazilian learners. In: BAPTISTA, B. O.; WATKINS, M. A. (Eds.). English with a Latin Beat: Studies in Portuguese/Spanish - English Interphonology. Amsterdam: John Benjamins, 2006. p. 139-154

ROCA, Iggy. Generative Phonology: Linguistic Theory Guide. London; New York: Routledge, 1994.

SEBASTIÁN-GALLES, Nuria. Cross-Language Speech Perception. In: PISONI D.B.; REMEZ, R.E. (Eds.), Handbook of Speech Perception. Blackwell Publishers, 2005. p. 546-566.

SILVEIRA, Rosane. Perception and production of English initial/s/clusters by Brazilian learners. Revista brasileira de linguística aplicada, v. 2, n. 1, p. 95-119, 2002.

The influence of pronunciation instruction on the perception and production of English word-final consonants. Universidade Federal de Santa Catarina, Florianópolis, 2004. Unpublished doctoral dissertation

SOUZA, Ana Cláudia de. Estudo comparativo entre a estrutura silábica do português brasileiro $e$ do inglês americano. Federal University of Santa Catarina, Florianópolis, 1998. Unpublished master thesis.

WATKINS, Michael. Variability in vowel reduction by Brazilian speakers of English. Universidade Federal de Santa Catarina, 2000. Unpublished doctoral dissertation.

YILDIZ, Yasemin. The structure of initial /s/-clusters: evidence from L1 and L2 Acquisition. In: TZAKOSTA, M.; LEVELT, C.; WEIJER, J. V. d. (Eds.). Developmental Paths in Phonological Acquisition. Special issue of Leiden Papers in Linguistics, 2005. p. 163-187.

Submetido em: 25/06/2015

Aceito em: 31/08/2015 
BetToni, M.; CAMPos, F. R. G. Preceding Phonological content and Cluster type efFects on word...

Revista Letras, Curitiba, N. 92 P. 133-152, JUL/DEZ. 2015.

ISSN 2236-0999 (VERSÃo ELETRÔNICA) 